\title{
Different Paths to the Same End: A Response to the Question: Quo Vadis?
}

\author{
Kathleen N. Fenton ${ }^{1}$ Marcello Cardarelli ${ }^{1}$ \\ ${ }^{1}$ The William Novick Global Cardiac Alliance, Memphis, Tennessee, \\ United States
}

Thorac Cardiovasc Surg 2015;63:80-82.
Address for correspondence Kathleen N. Fenton, MD, 14805 Maydale Ct., Silver Spring, Maryland, 20905, United States (e-mail: kathleennf@gmail.com).
We read with interest and enthusiasm the recent article by Yankah and colleagues "Cardiac Surgery Capacity in SubSaharan Africa: Quo Vadis?" and would like to add our thoughts to this discussion of where we are headed in our efforts to establish sustainable cardiac surgical programs in the developing world. The referenced paper contributes an excellent survey of the current status of cardiac surgery on the African continent to the growing literature on this topic, and will hopefully raise awareness and stimulate interest among surgeons so that more help can be provided. It also opens the door to the forthcoming discussion: Is there an optimal way to foster program development?

As residents, perhaps all of us have had the experience of being taught by each intensive care unit staff member that his or her preferred approach to weaning a patient from the ventilator was the only good method. In the end, we hopefully learned that many systems work, and also that the result depends more on the patient than on anything else. Cardiothoracic surgeons involved in international assistance work are similarly coming to realize that the same is true for sustainable program development: different approaches may be effective, but, finally, results are mostly determined by the local team.

As Yankah and colleagues point out, there is now general agreement on two issues. First, although a small number of patients can be helped by "evacuation" to established centers where they can be successfully treated, this system is not costeffective, helps very few patients, and contributes nothing to the betterment of the health care system in the native country. Having a surgical team make a one-time trip, the so-called medical tourism or surgical safari, though perhaps slightly more useful in terms of cost-effectiveness and (almost negligible) teaching, is also generally condemned as not being helpful in the long term. The solution to the shortage of cardiac surgery programs worldwide requires an enduring commitment to a specific site so that mentoring in both medical and leadership skills can be provided. Yankah presents three models: one led by a local surgeon, one consisting of foreign teams making teaching trips once or twice a year, and one where there is an expatriate surgeon living on site and heading the program. He seems to conclude that the first model is the unambiguous best.

While we agree that program sustainability depends ultimately on local leadership and local funding, we feel that each site has unique needs and the approach to achieving the desired end must be individualized. $\mathrm{We}^{1}$ and others ${ }^{2}$ have reported good results with medical mission trip models similar to Yahkah's model 2, as well as by having an on-site expatriate surgeon. ${ }^{3}$ In fact, more than one model may be used in the same place, with changes being made as the program progresses. A successful effort will, in general, result in the local surgeon progressively assuming a leadership role such that "model 2" and "model 3" programs ultimately become "model 1" programs.

We commend Yankah and colleagues for their excellent work, and thank them for bringing this important problem to the attention of the journal's readership.

\section{References}

1 Novick WM, Stidham GL, Karl TR, et al. Paediatric cardiac assistance in developing and transitional countries: the impact of a fourteen year effort. Cardiol Young 2008;18(3):316-323

2 Dearani JA, Neirotti R, Kohnke EJ, et al. Improving pediatric cardiac surgical care in developing countries: matching resources to needs. Semin Thorac Cardiovasc Surg Pediatr Card Surg Annu 2010;13(1):35-43

3 Fenton KN, Castillo SH, Claro CD, Novick WM. Teamwork and program organization in developing countries. World J Pediatr Congenit Heart Surg 2011;2(2):219-224 received

September 17, 2013

accepted

November 3, 2013

published online

December 23, 2014 (c) 2015 Georg Thieme Verlag KG

Stuttgart · New York
DOI http://dx.doi.org/ 10.1055/s-0034-1396597. ISSN 0171-6425. 


\section{Reply by the Authors of the Original Article}

\author{
Charles Yankah ${ }^{1}$ \\ ${ }^{1}$ Charité Medical University Berlin and German Heart Institute, Berlin, \\ Germany
}

We would like to thank the authors for their comments titled "Different paths to the same end" concerning our article "Cardiac Surgery Capacity in Sub-Saharan Africa (SSA)." We concur with their constructive analysis of our study. Their comments on the three models for developing cardiac programs in underserved regions in SSA reflect well on their similar experience and observations.

Despite the limited capacity in cardiac surgery programs in SSA (excluding the Republic of South Africa-RSA), it is confounded by a lack of independent departments for the subspecialties, adult and pediatric cardiology. The fact that the cardiologists who are practicing in SSA are integrated into the departments of medicine and pediatrics for routine clinical work and are dependent on their
Address for correspondence Charles Yankah, MD, PhD, Charité Medical University Berlin and German Heart Institute, Augustenburger Platz 1, 13353 Berlin, Germany

(e-mail: yankah@dhzb.de; cyankah@web.de).

department heads-who are noncardiac specialists-impedes any strategic plan for developing a "heart team" and a sustainable cardiac program. This is a great concern of many international visiting teams who intend to develop an infrastructure toward this goal. This prerequisite, independent cardiology departments to establish sustainable centers of excellence in cardiovascular medicine in SSA under good leadership and governance, was not addressed properly in our article.

This comment therefore is a second wake-up call that addresses the policy makers in SSA (excluding RSA) who have the vision to establish a regional hub of cardiac surgery services for their cardiac patients intending to minimize cardiac medicine tourism. 